\title{
Effect of air pollution on lung function of road side hawkers
}

\section{Pawan Kumar ${ }^{1}$, Sonisha Gupta ${ }^{2}$, Smita Asthana ${ }^{3}$}

${ }^{1}$ DTCD, Chest Physician ABVIMS \& Ram Manohar Lohia Hospital, New Delhi; ${ }^{2}$ MD (Chest), HOD Respiratory Medicine, Santosh University, Ghaziabad, Uttar Pradesh; ${ }^{M}$ MD (PSM), Scientist-E, NICPR-ICMR, Noida, Uttar Pradesh

\begin{tabular}{|c|c|c|c|c|c|c|c|}
\hline Abstract & Introduction & Methodology & Results & Conclusion & References & Citation & Tables/ Figures \\
\hline \multicolumn{8}{|c|}{ Corresponding Author } \\
\hline \multicolumn{7}{|c|}{$\begin{array}{l}\text { Dr. Pawan Kumar, House no } 517 \text { Block C\&D Pocket-1, Shalimar Bagh New Delhi } 110088 . \\
\text { E Mail ID: pawan.kumar@rmlh.nic.in }\end{array}$} & 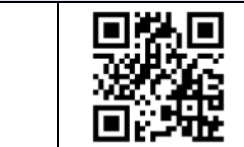 \\
\hline
\end{tabular}

\section{Citation}

Kumar P, Gupta S, Asthana S. Effect of air pollution on lung function of road side hawkers. Indian J Comm Health. 2020;32(4):699-704. https://doi.org/10.47203/IJCH.2020.v32i04.015

Source of Funding: Nil Conflict of Interest: None declared

\section{Article Cycle}

Received: 11/12/2020; Revision: 19/12/2020; Accepted: 26/12/2020; Published: 31/12/2020 This work is licensed under a Creative Commons Attribution 4.0 International License.

\section{Abstract}

Background: There is increasing concern of ambient air pollution as a global threat to humans. The most prominent effect of air pollution is on lung function. The air pollution causes decline in lung function amongst high exposure populations. There are some most vulnerable groups who are chronically exposed to ambient air pollution like traffic policemen, roadside hawkers, Banjara community in India, E-Rickshaw drivers etc. Methods: A cross sectional study was conducted in East Delhi, India. Spirometry was done for roadside hawkers having high exposure to ambient Air pollution and working daily for 6-8 hours for the last more than 3 years. The low exposure group was taken from personnel working inside offices. The spirometry parameters of both the groups were compared. Student ' $T$ ' test was applied for statistical analysis with the help of SPSS software. Results: Comparison of FVC, FEV1 and FEV1/FVC ratio among two groups revealed lower values for the high exposure group which was statistically significant. Among high exposure group the mixed pattern of ventilation defect was observed. Among low exposure group normal pattern of lung function was observed. Conclusion: Roadside hawkers are a vulnerable group to ambient air pollution resulting in their lower values of lung function parameters with resultant mixed ventilator defect and consequently high risk for development of respiratory diseases in the future.

\section{Keywords}

Ambient Air Pollution; Road-Side Hawkers; Lung Function; Spirometry

\section{Introduction}

Ambient air pollution (AAP) has been identified as a national problem since it is the fifth biggest cause of mortality in India.(1) and seventh in overall health burden. According to WHO,10 out of 20 most polluted cities are in India including, Delhi, Patna, Gwalior, Raipur etc.(2)PM level often exceeds the National Ambient Air Quality Standard (NAAQS) in more than 3/4th of Indian cities.(3)Sharma AK, Baliyan P, Kumar $\mathrm{P}$ et al.(4) conducted a study to look into the extent of air pollution, the magnitude of health problems due to air pollution and the risk relationship between air pollution and associated health effects in Delhi (India). 234 published articles in the PubMed 1996 onwards were reviewed. They stated that more systemic and well-planned studies on ambient air pollution are required to establish the extent of pollution and its impact on population of Delhi and extent of burden of cardiorespiratory diseases caused by air pollution and to fill up the gap in knowledge.

Development and urbanization over the past decade has led to rapid increase in the population of Delhi, the metropolitan city of India. Consequently, there 
has been a tremendous increase in the number of vehicles, which are causing very high levels of air pollution. Vehicular emissions are becoming the predominant source of air pollution in Delhi.(5)

There are certain groups of people who are particularly vulnerable to AAP because of their sustained exposure. Like traffic cops, road-side hawkers are regularly exposed to air pollutants. Drivers of public transport vehicles i.e., bus, auto, taxi, rickshaw etc., are also vulnerable to the consequences of air pollution. Besides, people who have to travel regularly for professional requirements in metropolitan cities are also exposed to air pollutants. Shopkeepers of shops located at large crossings and roadsides are as well exposed to air pollutants. (http://timesofindia.indiatimes.com/ citynagpur/Traffic-cops-falling-prey-to-lung diseases /article show /47620826.cms). SA Rizwan et al published a paper titled "air pollution in Delhi: Its magnitude and effects on health." In this authors analyzed the WHO report, report from the ministry of environment and forests, CPCB and other studies related to air pollution in Delhi.(6)This paper provides the evidence based insight into the status of air pollution in Delhi. The Delhi exceeds the maximum PM 10 limit by almost 10-times at $198 \mu \mathrm{g} / \mathrm{m} 3$ having a major contribution from vehicular pollution (67\%), followed by coal-based thermal power plants (12\%). A case control study was conducted by Vimercatil.et al. and it was concluded that exposure to air pollution is associated with increased morbidity from cardiovascular diseases, lung cancer, respiratory and allergic diseases.(7) Bajaj et.al. and various Studies done in Bogotá (Colombia)Kathmandu Nepal, Pondicherry Patiala, have found that chronic exposure to air pollution leads to deranged lung function. $(8,9,10,11,12)$ It was observed that amongst population of Delhi in comparison to rural there is higher prevalence of deranged lung function (obstructive, restrictive or mixed) , upper respiratory symptoms, lower respiratory symptoms and other respiratory morbidity. Mary B. Rice et.al. found that the nearer the houses to main road the greater is the derangement of lung function, indicating adverse effects of air pollution on lung function.(13) The restrictive spirometric pattern resulted from chronic exposure to ambient air pollution is associated with substantial morbidity and mortality burden.(14) Newwell $K$ et al did a systematic review and metaanalysis of studies published and found long term exposure is associated with increased cardio pulmonary mortality.(15)

\section{Aims \& Objectives}

To frame guidelines for preventive measure and early intervention to decrease the morbidity and mortality among road side hawkers.

\section{Material \& Methods}

The design of the study was cross sectional. The sampling approach was the Quota Sampling. Quota sampling is a type of Non-Probablistic sampling in which the target population is divided into mutually exclusive subgroups also called strata, based on their peculiar features or traits. The study was undertaken on 150non smoker subjects from Luxminagar and Pandav Nagar in east Delhi where AQI remain in the range of moderate to severe throughout the year. Out of this 75 were Road side hawker having high exposure to ambient air pollution and other 75 were official personnel considered low exposure group. The high exposure was comparable to low exposure group in age, height, weight and BMI. Ethical clearance was sought from institutional ethical committee. It was a field study in which respiratory health camps were organized. Three days before conducting the health checkup camp, the advertisement was done by distributing the pamhlettes amongst the target population (Raodside hawkers as well as office personnel) both in English and Hindi. The subjects who fulfilled the inclusion criteria were enrolled in the study after obtaining written informed consent. A structured proforma was filled for each subject followed by PFT.

Inclusion criteria: In the high exposure group: The subjects chosen were male, roadside hawkers, nonsmokers who are working daily for 6 to 8 hours and for more than three years.

In the low exposure group: The subjects chosen were nonsmoker male, office personnel.

In both the groups the subjects of 18 to 65 years of age were included in the study.

The exclusion criteria: Any history of: smoking, bronchial asthma, cardiovascular diseases, neuromuscular disorders, pneumonia, pleurisy and tuberculosis. Any history of cardiovascular, thoracic or abdominal surgery. In addition, persons who are unable to perform PFT and having any other systemic disease which have direct or indirect effect on PFT parameters were excluded from study.

Spirometry Measurement: Spirometry is a tool to measure the volumes of air that the patient can 

expel from the lung after maximal inspiration. The indices derived from this forced exhalation are compared with predicted normal values determined on the basis of age, height, sex and ethnicity. Spirometry helps in confirming the airway diseases. It detects airways obstruction/Restriction and provides an index of severity of disease. There are many different types of spirometer with varying different costs. The portable battery-operated spirometer of model MIR (Medical international Research) SNA23-053.06539 REF Spirolab III colour was used for performing PFT.The spirometry was performed as per the ATS/ERS guidelines (2005) and taking all infection preventive measure. The person was made to sit comfortably on stool or armed chair with back straight. For each patient a clean disposable mouth piece was used. The information of patients required to conduct the spirometry such as of height, weight, age, ethnicity and sex were entered in the software of spirometer. An adequate test requires a minimum of three acceptable FVC manoeuvres. The best of three was considered. Acceptable repeatability is achieved when the difference between the largest and the next largest FVC is $\leq 0.150 \mathrm{~L}$ and the difference between the largest and next largest FEV1 is $\leq 0.150$ L. (16)

Statistical Analysis: Age, Height, Weight and BMI were the independent variables. FVC, FEV1 and FEV1/FVC were the dependent variables. For these data mean and SD were calculated and presented as mean \pm SD for each of the parameters. Two groups were compared by applying independent student ' $T$ ' test using SPSS software. The statistical significance was indicated by ' $P$ ' value $<0.01$. Software SPSS 16.0 was used for data analysis amongst study group.

\section{Results}

Anthropometric Parameters (Table 1): The comparison of age, height, body weight and BMI between the two groups is given in table below. It was found that there is no significant difference between two groups.

The anthropometric parameters of high and low exposure groups compared using independent student $\mathrm{t}$ test. age, height, weight, and $\mathrm{BMI}$ of high risk group (as mean \pm SD) were $43.27 \pm 13.0$, $166.26 \pm 7.72,69.65 \pm 12.01,25.27 \pm 4.53$ respectively when these parameters were compared with the age, height, weight, and $\mathrm{BMI}$ (as mean $\pm \mathrm{SD}$ ) of high risk group i.e. 35.59 \pm 13.53 , 167.59 \pm 7.76 , $71.64 \pm 12.25,25.63 \pm 5.00$ respectively. It was found that there was no statistically significant difference between two groups for age, height, weight and BMI. Spirometry Parameters: Before the interpretation of spirometry results three factors have to be confirmed: (1). the flow-volume loops are free of artefacts and abnormalities.(2).the volume -time curve reaches a plateaue, and the expiration lasts at least 6 seconds.(3). results of best two efforts are within 0.2 liters of each other. The three parameters considered for analysis were FVC in liters, FEV1 in liters and FEV1/FVC ratio. Based on FVC, FEV1 and FVC/FEV1 ratio, ATS/ERS task force (standardization of lung function testing) describe obstructive, restrictive and mixed pattern of deranged lung function. $(16,17,18)$

Glossary of terms related to pulmonary function test: FEV1: forced expiratory volume in one second: total volume of air a patient is able to exhale in the first second during maximal effort. Its is measured in liter.

FVC, forced vital capacity: total volume of air a patient is able to exhale for the total duration of the test during maximal effort. It is measured in liter. FEV1/FVC ratio: the percentage of the FVC expired in one second

As per the recommendation by ATS documents published in 2017,FEV1,FVC and FEV1/FVC are the three parameters most important in routine clinical practice. However many other parameters can be calculated but most do not add clinical utility. (17) The FVC, FEV1 and FEV1/FVC ratio were compared between two groups (Table 2). The data were presented as mean \pm SD

The absolute values of FVC $(L)$ and FEV1(L) presented as Mean \pm SD were 2.68 \pm 0.06 and $2.06 \pm 0.68$ among high exposure group and $3.65 \pm 0.64$ and $2.90 \pm 0.74$ among low exposure group. The FVC and FEV1 were significantly lower amongst high exposure group than low exposure group ( $P$-value $<0.001$ ).

The FEV1/FVC ratio presented as Mean \pm SD were 78.28 \pm 13.41 and $82.98 \pm 12.11$ amongst High exposure $(\mathrm{N}=75)$ and Low exposure $(\mathrm{N}=75)$ respectively. The difference of FEV1/FVC ratio between high exposure group \&low exposure group was not statistically significant ( $P$-value $>0.001$ ).

When the spirometric parameters of high exposure group were analyzed within the group (Table 3 ), it was found that the observed value of both FVC and FEV1 were less than $70 \%$ of predicted values. The observed value of FEV1/FVC ratio was $78.28 \%$ i.e. less than $80 \%$. Therefore, within the group there was 
a mixed respiratory derangement with decrease in all three parameters. However, post bronchodilator spirometry was not performed to see any improvement in lung volumes.

When the spirometric parameters of low exposure group were analyzed within the group (Table 4), it was found that the observed value of both FVC and FEV1 were more than $70 \%$ of predicted values. The observed value of FEV1/FVC ratio was $82.98 \%$ i.e. more than $80 \%$. Therefore, within the low exposure group the lung function was found to be within normal limit.

The present study demonstrates the adverse effect of ambient air pollution on lung function of the roadside hawkers leading to decrease in lung function among high exposure group in comparison to low exposure group.

\section{Discussion}

The effect of air pollution has been studied in India and abroad on various groups of subjects and it has been observed that ambient air pollution has adverse effects on lung function of adults and poor development of lung function in children $(19,20,21)$. The group of road side hawker which I have chosen has never been studied and is one of the most vulnerable to ambient air pollution due to chronic exposure to ambient air pollution owing to their nature of work. It has been hypothesized that inhaled particles provoke the generation of reactive oxygen species. This, as well as direct damage by highly oxidative gases such as ozone and NO2, induces oxidative stress and inflammatory responses. $(22,23,24)$. Epigenetics has been proposed as one of the links between exposure to air pollution and respiratory health effects. $(25,26)$ In studies of human histological lung tissue, correlations have been observed between exposure to high PM levels and small airway remodeling by greater amounts of fibrous tissue and smooth muscle cells.(27)

Int Panis et al. (28) studied the association between daily changes in air pollution and lung function in healthy adults. Forced Vital Capacity (FVC), Forced Expiratory Volume in the first second (FEV1), FEV1/FVC and Peak Expiratory flow (PEF) from a cohort of 2449 employees were associated with daily measurements of PM10, NO2 and ozone at a nearby monitoring station in the North of Belgium. The author concluded a negative associations between daily variations in ambient air pollution and FVC,
FEV1 and PEF in healthy adults. The present study was undertaken in areas having air quality in the range of moderate to high category however the daily variation in level of pollutant were not measured. The subjects having chronic exposure in areas having moderate to high air pollution with more than three years of duration were studied however I didn't further classify the duration of exposure. In this study also the significant decline in parameters of FVC and FEV1 were found amongst high exposure group in comparison to low exposure group, but the PEF is not analyzed. Priftis KN et al recruited 478 and 342 children aged $8-10$ years living within a short radius around the urban and rural area monitoring stations, respectively and the results suggested that long-term exposure to urban environment is associated with sub-clinical airway narrowing and slower rate of FVC growth.(29) This study was undertaken in urban areas only on adult population with similar finding of decline in lung function but no follow up for further decline in lung function done. According to the World Health Organization, COPD is currently the sixth leading cause of death in the world, and further increases in the prevalence and mortality of the diseases predicted for the coming decades. The non-smoking causes like long term exposure to ambient air pollution has become leading cause of COPD. (30) The present study also indicates risk of development of COPD amongst nonsmoker road side hawker group because of clearly decline in lung function amongst high exposure group to ambient air pollution in comparison to low exposure group. There was decline in all three parameters i.e. FVC, FEV1, as well as FEV1/FVC ratio indicating mixed ventilatory defects.

To analyze the association of outdoor air pollution with chronic respiratory morbidity a cross-sectional study was conducted in one industrial town (study) and one non-industrial (reference) in Punjab state, northern India. Ambient air quality samples were collected and analyzed each week for $2 \mathrm{yr}$. Subjects were 3,603 individuals $>15 \mathrm{yr}$ old who were interviewed and whose lung functions were measured spirometrically. Their lung function was categorized in terms of obstructive or restrictive defects. Levels of total suspended particulates, nitrogen oxides, sulfur oxides, carbon monoxide, and ozone were significantly higher in the study town than in the reference town. Logistic regression analysis showed that residence in the study town 
was independently associated with spirometric ventilatory defect $(\mathrm{OR}=2.4 ; 95 \% \mathrm{Cl}=2.0,2.9 ; \mathrm{p}<$ 0.001 ) after controlling for other demographic effects.(30) In the present study high exposure as well as low exposure group is in urban area only but the level of exposure to ambient air pollution is different amongst two groups owing to their nature of work however in comparison the sample size was smaller in present study. Similar to the above study the high exposure group was found to have spirometric ventilatory defects. There was decrease in both FVC and FEV1, as well as FEV1/FVC ratio indicating mixed ventilatory defect.

The present study was done to include the group of roadside hawkers because this group has been overlooked as a vulnerable group to ambient air pollution. The findings of this study reinforce the findings of earlier lung function studies done on other groups who are chronically exposed to ambient air pollution. Roadside hawkers is highly vulnerable group to the ambient air pollution owing to their nature of work and some preventive and corrective measures need to be taken to protect their health. The preventive measures which can be reinforced are: wearing of mask, regular health checkup and respiratory function assessment and timely medical intervention to decrease respiratory mortality and morbidity amongst them.

\section{Conclusion}

The study clearly proved that long term exposure to ambient air pollution is associated with decline in lung function in the high exposure group in comparison to the low exposure group. In high exposure group, the study found the decrease in FVC, FEV1, as well as FEV1/FVC ratio.

\section{Recommendation}

Preventive measures such as wearing good quality filtering mask and giving them some protective semi closed or closed shop to minimize the direct effects of ambient air pollution.

\section{Limitation of the study}

The subjects having daily exposure to ambient air pollution were included in the study, however further classification of duration is not done. The daily variation in the parameters of air pollution not measured. Only three parameters of spirometry i.e. FEV1, FVC and FEV1/FVC\% were analysed and other parameters not analysed.

\section{Relevance of the study}

The study clearly proved that long term exposure to ambient air pollution is associated with decline in lung function in the high exposure group in comparison to the low exposure group.

\section{Authors Contribution}

PK: Collection, compilation of data, introduction and review of literature and final submission. SG; SA: analysis of data and discussion, contribution in interpretations and final submission.

\section{References}

1. Atkinson R.W., Cohen, Mehta A, Anderson S. Systematic review and Meta analysis of Epidemiological time -series. studies on outdoor air pollution and health in Asia. air quality atmosphere and Health 2011; 5: 383-91.

2. World Health Organization. WHO Global Urban Ambient Air Pollution Database (Update 2016). 2016.

3. Gargava P, Rajagopalan V. Source apportionment studies in six Indian cities-drawing broad inferences for urban PM10 reductions. Air QualAtmosHeal 2016;9(5):471-81.

4. Sharma AK, Baliyan P, Kumar P. Air pollution and public health: the challenges for Delhi, India. Rev Environ Health. 2018 Mar 28;33(1):77-86. [PubMed]

5. RatiSindhwal,PramilaGoyal. Assessment of traffic -generated gaseous and particulate matter emissions and trends over Delhi (2000-2010).Atmospheric pollution research. 2014;5,(3):438-46.

6. Rizwan S, Nongkynrih B, Gupta SK. "Air pollution in Delhi: Its Magnitude and Effects on Health". Indian J Community Med. 2013;38(1):4-8. [PubMed]

7. Vimercati L, Gatti MF, Baldassarre A, Nettis E, Favia N, Palma M, Martina GL, Di Leo E, Musti M. Occupational Exposure to Urban Air Pollution and Allergic Diseases. Int J Environ Res Public Health. 2015 16;12(10):12977-87..[PubMed].

8. Bajaj, Nishitha, et al. "Determinants of respiratory and cardiovascular health effects in traffic policemen: A perceptionbased comparative analysis." Journal of Transport \& Health (2017).

9. Estévez-García.et al. "Occupational exposure to air pollutants: particulate matter and respiratory symptoms affecting trafficpolice in Bogotá." Revista de SaludPública (2013);15.6: 870-85.

10. Shrestha, Hari Sunder, et al. "A cross-sectional study of lung functions in traffic police personnel at work in Kathmandu Valley, Nepal." Annals of Clinical Chemistry and Laboratory Medicine 2015; 1.1: 42-48.

11. Pal P, John RA, Dutta TK, Pal GK. Pulmonary function test in traffic police personnel in Pondicherry. Indian J Physiol Pharmacol. 2010;54(4):329-36. PMID: 21675030.[PubMed].

12. Gupta S, Mittal S, Kumar A, Singh KD. Respiratory effects of air pollutants among nonsmoking traffic policemen of Patiala, India. Lung India. 2011;28(4):253-7. doi: 10.4103/0970-2113.85685. PMID: 22084537; PMCID: PMC3213710.[PubMed].

13. Rice MB, Ljungman PL, Wilker EH, Dorans KS, Gold DR, Schwartz J, Koutrakis P, Washko GR, O'Connor GT, Mittleman MA. Long-term exposure to traffic emissions and fine particulate matter and lung function decline in the Framingham heart study. Am J Respir Crit Care Med. 2015 15;191(6):656-64.[PubMed]

14. Guerra $S$, Carsin AE, Keidel D, Sunyer J, Leynaert B, Janson C, Jarvis D, Stolz D, Rothe T, Pons M, Turk A, Anto JM, Probst-Hensch N. Health-related quality of life and risk factors associated with spirometric restriction. Eur Respir J. 2017 May 25;49(5):1602096. [PubMed]

15. Newell K, Kartsonaki C, Lam KBH, Kurmi OP. Cardiorespiratory health effects of particulate ambient air pollution exposure in lowincome and middle-income countries: a systematic review and 

meta-analysis. Lancet Planet Health. 2017;1(9):e368e380.[PubMed].

16. Pellegrino R, Viegi G, Brusasco V, Crapo RO, Burgos F, Casaburi R, Coates A, van der Grinten CP, Gustafsson P, Hankinson J, Jensen R, Johnson DC, MacIntyre N, McKay R, Miller MR, Navajas D, Pedersen OF, Wanger J. Interpretative strategies for lung function tests. Eur Respir J. 2005;26(5):948-68..[PubMed].

17. Bruce $\mathrm{H}$. et al. Recommendations for a Standardized Pulmonary Function Report, An Official American Thoracic Society Technical Statement.Am J RespirCrit Care Med.2017; 196: 1463-72.

18. Miller MR, Crapo R, Hankinson J, Brusasco V, Burgos F, Casaburi R, Coates $A$, Enright $P$, van der Grinten $C P$, Gustafsson $P$, Jensen $R$, Johnson DC, MacIntyre N, McKay R, Navajas D, Pedersen OF, Pellegrino R, Viegi G, Wanger J; ATS/ERS Task Force. General considerations for lung function testing. Eur Respir J. 2005;26(1):153-61..[PubMed]

19. Esposito S, Tenconi R, Lelii M, Preti V, Nazzari E, Consolo S, Patria MF. Possible molecular mechanisms linking air pollution and asthma in children. BMC Pulm Med. 2014 1;14:31. doi: 10.1186/1471-2466-14-31. PMID: 24581224; PMCID: PMC3941253. [PubMed].

20. Wong SL, Coates AL, To T. Exposure to industrial air pollutant emissions and lung function in children: Canadian Health Measures Survey, 2007 to 2011. Health Rep. 2016;27(2):3-9. PMID: 26885839.[PubMed].

21. Rice MB.et al Lifetime Exposure to Ambient Pollution and Lung Function in Children. Am J RespirCrit Care Med 2016 15;193(8):8818. doi: $10.1164 / \mathrm{rccm} .201506-10580$ C. 5,Issue 3, July 2014. Pages 438-446.

22. Perez L, Rapp R, Künzli N. The Year of the Lung: outdoor air pollution and lung health. Swiss Med Wkly. 2010 18;140:w13129. doi: 10.4414/smw.2010.13129. PMID: 21086200.[PubMed].

23. Romieu I, Garcia-Esteban R, Sunyer J, Rios C, Alcaraz-Zubeldia M, Velasco SR, Holguin F. The effect of supplementation with omega3 polyunsaturated fatty acids on markers of oxidative stress in elderly exposed to $\mathrm{PM}(2.5)$. Environ Health Perspect. 2008;116(9):1237-42. doi: 10.1289/ehp.10578. PMID: 18795169; PMCID: PMC2535628.[PubMed].

24. Gruzieva O, Xu CJ, Breton CV, Annesi-Maesano I, Antó JM, Auffray C, Ballereau S, Bellander T, Bousquet J, Bustamante M, Charles MA, de Kluizenaar Y, den Dekker HT, Duijts L, Felix JF, Gehring U, Guxens M, Jaddoe VV, Jankipersadsing SA, Merid SK, Kere J, Kumar A,

\section{Tables}

[Effect of air...] | Kumar P et al Lemonnier N, Lepeule J, Nystad W, Page CM, Panasevich S, Postma D, Slama R, Sunyer J, Söderhäll C, Yao J, London SJ, Pershagen G, Koppelman GH, Melén E. Epigenome-Wide Meta-Analysis of Methylation in Children Related to Prenatal NO2 Air Pollution Exposure. Environ Health Perspect. 2017;125(1):104110. [PubMed].

25. Gref A, Merid SK, Gruzieva O, Ballereau S, Becker A, Bellander T, Bergström $A$, Bossé $Y$, Bottai $M$, Chan-Yeung $M$, Fuertes $E$, lerodiakonou $D$, Jiang $R$, Joly $S$, Jones $M$, Kobor $M S$, Korek $M$, Kozyrskyj AL, Kumar A, Lemonnier N, Maclntyre E, Ménard C, Nickle D, Obeidat M, Pellet J, Standl M, Sääf A, Söderhäll C, Tiesler CMT, van den Berge M, Vonk JM, Vora H, Xu CJ, Antó JM, Auffray C, Brauer M, Bousquet J, Brunekreef B, Gauderman WJ, Heinrich J, Kere J, Koppelman GH, Postma D, Carlsten C, Pershagen G, Melén E. Genome-Wide Interaction Analysis of Air Pollution Exposure and Childhood Asthma with Functional Follow-up. Am J Respir Crit Care Med. 2017 15;195(10):1373-1383.[PubMed]

26. Churg A, Brauer M, del Carmen Avila-Casado M, Fortoul TI, Wright JL. Chronic exposure to high levels of particulate air pollution and small airway remodeling. Environ Health Perspect. 2003;111(5):714-8. doi: 10.1289/ehp.6042. PMID: 12727599; PMCID: PMC1241480.[PubMed]

27. Int Panis L, Provost EB, Cox B, Louwies T, Laeremans M, Standaert A, Dons E, Holmstock L, Nawrot T, De Boever P. Short-term air pollution exposure decreases lung function: a repeated measures study in healthy adults. Environ Health. 2017 14;16(1):60. doi: 10.1186/s12940-017-0271-z. PMID: 28615020; PMCID: PMC5471732.[PubMed]

28. Priftis KN, Anthracopoulos MB, Paliatsos AG, Tzavelas G, NikolaouPapanagiotou A, Douridas P, Nicolaidou P, Mantzouranis E. Different effects of urban and rural environments in the respiratory status of Greek schoolchildren. Respir Med. 2007;101(1):98-106 doi: 10.1016/j.rmed.2006.04.008. Epub 2006 Jun 6. PMID: 16757161. [PubMed].

29. Tan WC, Ng TP. COPD in Asia: where East meets West. Chest. 2008;133(2):517-27. doi: 10.1378/chest.07-1131. PMID: 18252918; PMCID: PMC7094310.[PubMed].

30. Kumar R, Sharma M, Srivastva A, Thakur JS, Jindal SK, Parwana HK. Association of outdoor air pollution with chronic respiratory morbidity in an industrial town in northern India. Arch Environ Health. 2004;59(9):471-7. doi: 10.1080/00039890409603428. PMID: 16381489.[PubMed].

\section{TABLE 1 THE ANTHROPOMETRIC PARAMETERS OF HIGH AND LOW EXPOSURE GROUPS}

\begin{tabular}{|l|l|l|l|}
\hline Parameters & High Exposure group(N=75), mean \pm SD & \multicolumn{1}{|l}{ Low exposure group (N=75), mean $\pm S D$} \\
\hline Age (years) & $43.27 \pm 13.0$ & $35.59 \pm 13.53$ \\
\hline Height(cm) & $166.26 \pm 7.72$ & $167.59 \pm 7.76$ \\
\hline Weight (Kg) & $69.65 \pm 12.01$ & $71.64 \pm 12.25$ \\
\hline BMI (kg/m2) SD & $25.27 \pm 4.53$ & $25.63 \pm 5.00$ & 0.092 \\
\hline
\end{tabular}

TABLE 2 SPIROMETRY PARAMETERS BETWEEN HIGH EXPOSURE AND LOW EXPOSURE GROUP

\begin{tabular}{|l|l|l|l|}
\hline Parameters & High exposure (N=75) Mean \pm SD & Low exposure (N=75) Mean \pm SD \\
\hline FVC(L) & $2.68 \pm 0.66$ & $3.65 \pm 0.64$ \\
\hline FEV1(L/sec) & $2.06 \pm 0.68$ & $2.90 \pm 0.74$ \\
\hline FEV1/FVC ratio & $78.28 \pm 13.41$ & $82.98 \pm 12.11$ \\
\hline
\end{tabular}

TABLE 3 SPIROMETRY PARAMETERS OF HIGH EXPOSURE GROUP WITHIN THE GROUP

\begin{tabular}{|l|l|l|l|}
\hline Parameters & FVC (mean) & FEV1(mean) & FEV1/FVC (\%) mean \\
\hline Observed & 2.6807 & 2.0601 & 78.28 \\
\hline Predicted & 3.9137 & 3.1991 & 80.06 \\
\hline \%age of predicted & 68.50 & 64.40 & - \\
\hline
\end{tabular}

TABLE 4 SPIROMETRY PARAMETERS OF LOW EXPOSURE GROUP WITHIN THE GROUP

\begin{tabular}{|l|l|l|l|}
\hline Parameters & FVC (mean) & FEV1(mean) & FEV1/FVC (\%) mean \\
\hline Observed & 3.6581 & 2.9047 & 82.98 \\
\hline Predicted & 3.9521 & 3.2627 & 80.59 \\
\hline \%age of predicted & 92.56 & 89.03 & ----- \\
\hline
\end{tabular}

